\section{P135 PREVALENCE OF SENSITISATION TO SOYA FLOUR IN THE BAKING INDUSTRY WITHIN THE UK}

1J Cannon, ${ }^{2} \mathrm{M}$ Jones, ${ }^{2} \mathrm{~J}$ Welch, ${ }^{1} \mathrm{~B}$ Fitzgerald, ${ }^{1} \mathrm{~J}$ Szram, ${ }^{2} \mathrm{P}$ Cullinan. ${ }^{1}$ Royal Brompton Hospital, London, UK; ${ }^{2}$ Imperial College, London, UK

\subsection{6/thoraxjnl-2014-206260.276}

Introduction Soya flour is routinely used as a baking additive to increase shelf life, improve colour and introduce a nutty flavour to bread. Although a large number of bakers are exposed to soya flour, there is little information as to the prevalence of sensitisation to soya flour in the baking industry. One study reports sensitisation to soya flour in four bakers who were sensitised to flour and alpha amylase and a bronchial challenge to soya flour elicited an immediate or dual asthmatic response. Studies in soy processing plant (slightly different to bakeries) report soy-specific IgE in $21 \%$ of soy processing workers compared with only $4 \%$ in health care workers, suggesting soya is an important occupational allergen in the soy processing industry.

Methods To determine prevalence of sensitisation to soya flour in bakery workers, we carried out skin prick testing to soya flour (Allergopharma 598) in bakery workers exposed to soya flour $(\mathrm{n}=196)$ and in non-bakery controls $(\mathrm{n}=50)$, who attended an occupational lung disease clinic. Skin tests were categorised as positive if they induced a wheal with a mean diameter of $\geq 2$ $\mathrm{mm}$ greater than the response to a negative (saline) control and histamine was used as a positive control.

Results In a total of one hundred and ninety five bakery workers exposed to soya, forty two bakers were sensitised to soya flour (21\%), and forty of those bakers were also sensitised to either flour and or alpha amylase (95\%) In comparison, none of the control group $(\mathrm{n}=50)$ were sensitised to soya flour.

Conclusion In our preliminary study of bakery workers exposed to soya flour, we found that around a fifth of the population were sensitised to soya flour. The clinical significance of soya flour need further investigation, although it seems prudent to include soya flour in the diagnostic tests for bakers asthma.

\section{P136 ASTHMA IN ROYAL AIR FORCE (RAF) PERSONNEL: MEASURING SEVERITY, CONTROL AND PREVIOUS IMPACT ON SERVICE CAREER}

1J Szram, ${ }^{2} \mathrm{~S} J$ Schofield, ${ }^{3}$ IA Mollan, ${ }^{3} \mathrm{G}$ Davies, ${ }^{3} \mathrm{D}$ Bruce, ${ }^{2} \mathrm{P}$ Cullinan. ${ }^{1}$ Royal Brompton and Harefield NHS Foundation Trust, London, UK; ${ }^{2}$ National Heart and Lung Institute, Imperial College, London, UK; ${ }^{3}$ The Royal Air Force Medical Branch, UK

\subsection{6/thoraxjnl-2014-206260.277}

Background The overwhelming majority of UK military recruitment occurs in the age group (18-24) in which the recent increases in childhood asthma have been greatest. Concerns about operational risks associated with asthmatic individuals are reflected in selection policies excluding applicants taking asthma treatment, reporting symptoms in the last five years or since the age of 16 . This study was designed to characterise the severity and impact of asthma on current RAF serving personnel.

Methods Questionnaires were sent to all current service personnel with a diagnosis of asthma on their medical record; an equivalent number of non-asthmatic personnel (matched on age and sex) were also surveyed to provide a referent population. Information on asthma symptoms and treatment, reported change in deployment, medical fitness category and career intention was collected.

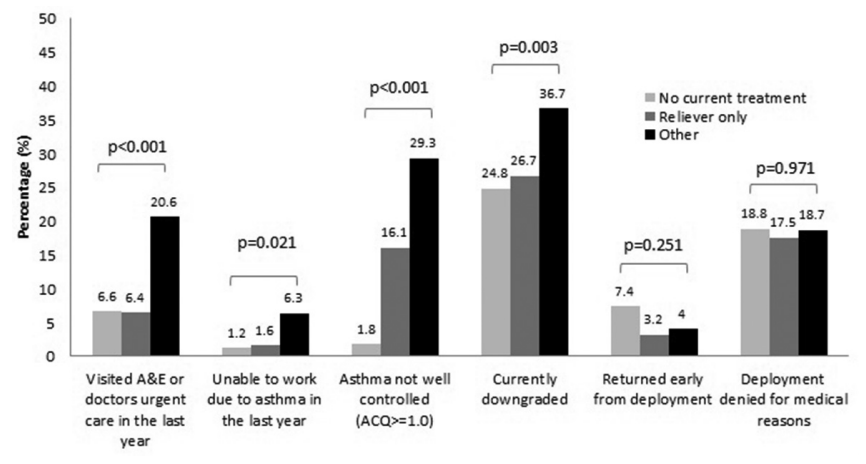

Abstract P136 Figure 1 Prevalence of asthma and service-related outcomes in RAF asthmatics, stratified by asthma treatment

Results Of 463 asthmatics who responded to the survey, 167 (36.1\%) were not currently on asthma treatment, 63 (13.6\%) were on reliever therapy only and $233(50.3 \%)$ were on regular asthma treatment. Two-thirds reported adult onset asthma. Those on regular treatment were more likely to have needed urgent/unscheduled treatment, been unable to work due to their asthma and have a current ACQ score indicating uncontrolled disease; whilst this group were more likely to be currently downgraded, they were no more likely to have returned early from deployment than those in other groups (Figure). Comparing individuals with asthma and matched referents, those with disease were significantly more likely to be downgraded (OR 2.36 (95\% CI 1.48-3.77), $\mathrm{p}<0.001$ ), prevented from deploying for medical reasons (OR 2.47 (95\% CI 1.41-4.34), $\mathrm{p}=0.006)$ and be assigned unfit (OR 1.79 (95\% CI 1.20-2.73, p = 0.006)). Very few individuals had to return early from deployment, suggesting that restrictions were effective in mitigating risks posed by uncontrolled asthma.

Conclusions The findings from this cohort suggest that asthmatics in the RAF, particularly those taking regular treatment, are being restricted from some jobs and environments; this affects few individuals and does not appear to have a negative impact on service career. Decisions at recruitment are likely to have greater impact and would benefit from being studied prospectively.

Abstracts M137 to M148 on page A212-218.

\section{Predicting clinical outcomes in acute respiratory illness}

\section{P149 CHARACTERISTIC AND PROGNOSIS OF PATIENTS WITH COPD AND TYPE 2 RESPIRATORY FAILURE}

T Spruell, C Dave, R Mukherjee, AM Turner. Birmingham Heartlands Hospital, Birmingham, UK

\subsection{6/thoraxjnl-2014-206260.278}

Introduction Factors associated with type 2 respiratory failure (T2RF) in COPD have been poorly described. Co-existent obstructive sleep apnoea is thought to play a part, ${ }^{1}$ and episodes of worsening hypercapnia, associated with acidosis (AHRF), at the time of exacerbations is a well recognised feature. ${ }^{2}$ We hypothesised that the development of hypercapnia or type 2 respiratory failure would associate with a higher risk of subsequent AHRF and higher mortality.

Methods 292 patients who had been prescribed oxygen for their COPD during 2006-2010 were studied. Medical records were 